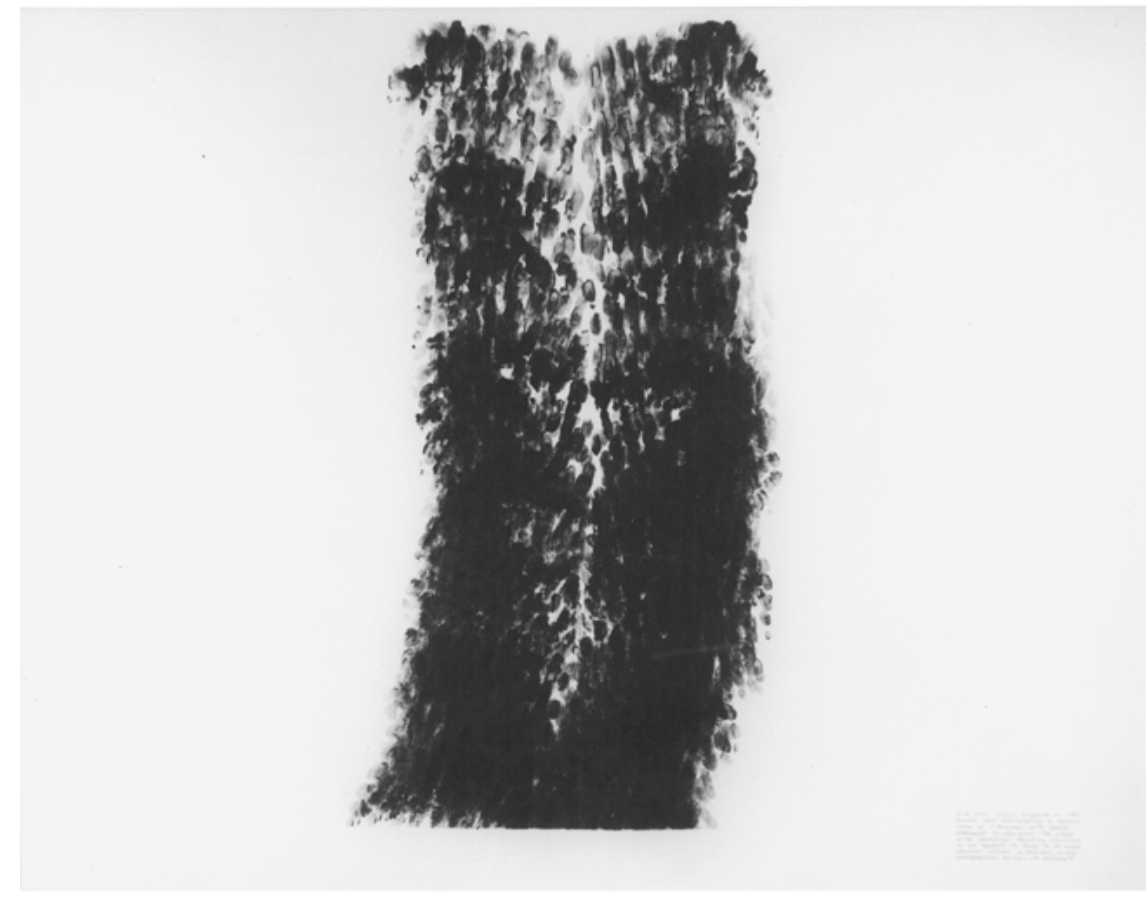

Fig. 12: Robert Morris, Blind Time I, 1973, graphite and paint oil on paper, $89 \times 117 \mathrm{~cm}$. (C) Robert Morris / Artists Rights Society (ARS), New York (Courtesy of Castelli Gallery). 


\section{The Weak Relations of Touch and Sight through the Passage of Lapsed Time}

Can one be ephectic otherwise than unawares? [...] I don’t know. I think that's all, for the moment. I see nothing else (I see nothing whatever), for the time being.

Samuel Beckett, The Unnamable

For some, reality is not enough. Others, perhaps those whose anxieties have been deadened by lethargy and inactivity, find in the inert forms of reality a rare intoxication. The shapes of the physical world, once assimilated, become detached identities. The random dimensions of reality lose their subjectivity. Duration becomes a coefficient of weight.

Mel Bochner and Robert Smithson, The Domain of the Great Bear

Since, then, we are looking for the principles of perceptible body; and since perceptible is equivalent to tangible, and tangible is that of which the perception is touch, it is clear that not all the contrarieties constitute forms and principles of body, but only those which correspond to touch. For it is in accordance with a contrariety-a contrariety, moreover, of tangible qualities-that the primary bodies are differentiated.

Aristotle, On Generation and Corruption 329b7-10

In the introduction to Continuous Project Altered Daily, Robert Morris reflected on the written compilation of his artistic practice, pondering the incredulous nature of his mind. "Perhaps," he wrote,

a skeptical and speculative turn of mind has always presided over the work and the writing. I never set out to prove or demonstrate so much as to investigate. And I never set out to affirm so much as to negate (finding that the former flowed from the latter in any case). Change and not continuity has been the guide-Heraclitus not Anaximander lit the path. Paradox and the fugitive were always more attractive than assured style and stable position. Rupture and disruption, not any organic development, provided the dynamic. [... ] One of the first things I set out to shatter for myself, was the unity of a subject-both with itself and with a monolithic, coherent style prescribed to flow from this ideological oppression. ${ }^{1}$

Morris's sceptical and speculative turn of mind rendered his artistic practice as a continuous investigation that employs the activity of sképtomai-that is, inquiry as

On 28 November 2018, Robert Morris died. If this piece, written a few months prior to his passing, initially touched his work from a distance, it has now become a kind of reminiscent trace. This research was conducted at the Maimonides Centre for Advances Studies - Jewish Scepticism (DGFFOR 2311) in Hamburg University. I thank Rachel Aumiller and the research fellows at the Centre for their illuminating responses to oral presentations of some of these ideas, especially to Prof. Giuseppe Veltri, Racheli Haliva and Stephan Schmid. My gratitude to the Castelli Gallery in New York for their generosity in granting the release rights for Robert Morris Drawings. 
an ongoing activity-as a way of life that constantly opposes dogmatism. He allies his work with that of the sceptical philosopher forging sceptical tactics of examination and inquiry as modes posed in opposition to the rule of demonstration and affirmation in order to resist ideological oppression. However, unlike the sceptical philosopher's modes of mental exercise, which challenge perception and reasoning as sources of knowledge, Morris investigated the concepts of change, paradox, rupture, and disruption by engaging in embodied praxis. This kind of scepticism was risky. It was unsafe and uncertain; an example was his 1971 interactive installation at the Tate Gallery in London, which notoriously closed after visitors were injured when engaging with the sculptural apparatus. Another was his series Blind Time Drawings, which commenced in 1973 and was produced over several decades. This essay will concentrate on these drawings, in which the artist examines the pictorial practice through the paradoxical relations between perception and intelligibility; in particular, that of sight in proximity to touch. It will show that the drawings perform the pictorial manner by concentrating on the haptic movements of the artist's hands while working in blindness, thus posing the question of how sense perception relates to the attainability of knowledge. They also reveal Morris's concern with the process of creation and the measure of time. The drawings present two different temporal processes which tie the activity of painting to the creation of self. The artist's intention to shatter the unity of the subject is performed in his blind haptic activity as a mode for casting doubt on the fabrication of such unity. During an examination of several works in the series, two questions will be posed: If Blind Time Drawings traces the ongoing activity of touch, what temporal schemes does it engender? And what problematics does it reveal for the becoming of an image, and of a self, contingent upon the continuity of time?

The problem of the role of the senses and perception was prevalent among Morris's contemporaries. Artists seeking to withdraw from the clear relation between art and representation experimented with the displacement of the senses and the suspension of the gaze. While for artists, clear sight no longer denoted the validity of knowledge, the French deconstructive critique of logocentrism crossed the Atlantic and entered the American discourse. Art and philosophy could no longer denote truth in terms of signification. In conjunction with this shift, North American artists from the East Coast to the West experimented with media, performance, the body, the sensual organs, eyes, vision, gaze, hair, hands, fingertips, nails, cheeks, feet, gravity, brain, weight, ears, sound, nose, smells, mouth, voice, skin, and tactility-technē. These experimental artistic practices embraced contingency and indeterminacy as an unconventional telos bounded by materiality, the only means for creation without end. Morris's Blind Time Drawings, which casts doubt on the perceiving mind, critiques its ability to produce true knowledge while returning to the problem of the medium now placed within the performing body of the painter. In this series, Morris practises haptic drawing as a means of unhinging sense perception from intelligibility and the pictorial from visuality. 
Alongside his contemporaries Robert Smithson, Mel Bochner, and Michael Snow, Morris scrutinised sight and visuality as they were laid bare and dissected, not for the sake of anchoring knowledge in certitude, but as a shearing of their strong connections to the sovereignty of forged knowledge, technology, information, media culture, and their dominant effect on the construction of clear perception. Akin to the sceptic's intervention that seeks to critique the manner we attain knowledge, they returned to the problem of sense. They examined perception by impeding and inundating the perceiving sensual organs, removing them from their habitual operations. In Blind Time Drawings, Morris coupled sight with touch as a mode of performing the weak relations of measured time. However, in order to understand his trajectory, I will begin by setting the stage of his generation.

\section{The Quasitranscendental Blind Spot}

In 1965, while working on the visual apparatus for Enantiomorphic Chambers, Robert Smithson suggested "Stopping of sight, not by brutal opposition but by lowering the 'head'-foam-top developed-hands in pockets. Imperfect flatness; one type of destitution that has fallen into disuse." 2 This aporetic statement exposed the incredulity of sight and its strong connection to thought. It appeared in After Thought, a photocollage composed around a photograph by artist Dan Graham. The collage depicted Smithson's torso from the back, bending with his head down and his hands in his pockets. The figure is concealed by an intersection of two diagonal lines drawn from two photographs of stereoscopic boxes clasping its sides. The overlaying material is a cancelling chiasmic sketch of a two-dimensional apparatus mimicking two eyes. The work comprises Smithson's investigation of sight for Enantiomorphic Chambers, where two metal constructions with mirrors mounted on a wall exposed a blind spot in the viewer's fixed visual field. In his statement for the Art in Process exhibition catalogue (1966) entitled "Interpolation of the Enantiomorphic Chambers," he explained that the installation examined seeing one's own sight, creating a split and reverse vanishing point that made blindness visible, in infinite myopia. " "It is a known fact," he wrote in a draft, "that we do not see with our eyes but rather with our brain. Thinking about one's sight enables one to build or invent a structure that sees nothing." Myopic nothingness, in a "sense establishes a certain kind of

2 Cited from Robert Smithson's Afterthought: Enantiomorphic Chambers, 1965, photocollage, staples, coloured pencils, graph paper, Museu Fundação de Serralves, Portugal.

3 Robert Smithson, "Interpolation of the Enantiomorphic Chambers" [Art in Process, 1966], in Robert Smithson: Collected Writings, ed. Jack Flam (Berkeley: University of California Press, 1996), 39-40. 4 Robert Smithson, draft of "Interpolation of the Enantiomorphic Chambers," in Robert Smithson and Nancy Holt Papers, 1905-1987, AAA, Smithsonian Institution, Washington, DC, reel 3834, frame 994. See also Eugenie Tsai and Cornelia Butler, eds., Robert Smithson (Berkeley: University of California Press, 2004), 138-39. 
point of departure not so much toward the idealistic notion of perception, but all the different breakdowns within perception. So that's what I'm interested in. I'm interested in zeroing in on those aspects of mental experience that somehow coincide with the physical world."5 Smithson's quasi-transcendental study of perception, particularly the operation of the senses and the interval between mental images and the world, was positioned as a self-cancelling system in which logic is suspended. One way in which he could scrutinise sense perception, particularly sight, was to impede specific elements of the mechanics of sight while demonstrating these very operations through their art-medium correlates.

In 1967, Mel Bochner scrutinised the demonstrative certainty produced by visual evidence. He investigated the contraptions of visual perception from perspective and performance to photography. "Perspective," he wrote in The Serial Attitude (1967), "almost universally dismissed as a concern in recent art, is a fascinating example of the application of fabricated systems. In the works of artists like Uccello, Dürer, Piero, Saenredam, and Eakins (especially their drawings), it can be seen to exist entirely as a methodology. It demonstrates not how things appear but rather the workings of its own strict postulates." In Bochner's review of art critic and curator Lawrence Alloway's exhibition Systemic Painting at the Guggenheim (Arts Magazine, 1966), he deemed pictorial seeing to be a convention that the new art was to expose as actually being a mode of fabricated vision: "Whatever else painting has been, it has been an art form which endured a number of radical shifts of intent. What originated and existed for a long period as a means of representation has in rapid succession become a means aware of itself, involved with itself and finally a thing-in-itself."7 This awareness of the means of artistic production was to rewire the split of self-reflection not as a circular mode, but a chiasmic one. The rupture of self-reflection decreed a divide and a withdrawal from a return to an image of representation, for the coming-into-form of the image was now contingent on the exposition of the self-reflective medium. Hence, as Bochner implies, once painting was exposed as a medium, its self-reflective movement created a chiasmic intersection that weakened the hold of its own image. The difference between the exposition of the medium and its own image marks a knot, or a disturbance in the chiasmic order. Rendering apparent the conditions of knowing and being and those of the interval between representation and presence was a means of generating self-referentiality and autonomy (self-rule) contingent on the separation and suspension of mind and body, sense (as logos, articulation, signification) and sense (as sensual perception), as well as the

5 Reynolds, "Enantiomorphic Models," in Robert Smithson, 140, n. 18: Robert Smithson, interview with Denis Wheeler, reel 3833, frame 1124; Smithson, Robert Smithson: Collected Writings, 208.

6 Mel Bochner, “The Serial Attitude,” in Solar Systems \& Rest Rooms: Writings and Interviews, 19652007 (Cambridge, MA: The MIT Press, 2008), 45 (originally published in Artforum 6, no. 4 [1967]: 2833).

7 Mel Bochner, “Systemic Painting”, in Solar Systems \& Rest Rooms, 14 (originally published in Arts Magazine 41, no. 1 [1966]: 57-58). 
discontinuity of the perceiving senses. The analysis of perception led to the fragmentation of its operative organs, those sensory mediating gadgets and their technological extensions, to place them in suspension, un-synthesised and at times obstructed and thus degenerated (that is, techne as degenerated; unfunctional, unproductive, in stasis). Drawing became a speculative tool for experimentation with the conditions of visibility.

In “Perverse Perspectives” (1967), art critic Lucy R. Lippard showed how artists of this period were engaging with the paradox of the visual via the exposition of its distorting nature. ${ }^{8}$ What is interesting is that the problem posed by visuality was not restricted to painting, but was regarded as the crux of modes of knowing. What would happen if one were to knock, or to cut, an opening in the serial sequence of the proper order of perceiving gadgets or devices of production? A case in point is Michael Snow who constructed vision-impeding objects in sculpture, photographs, installations, and film. As Julia Kristeva observes, Snow's film Wavelength (1967) performs the violence of the camera's zoom, as a schizophrenic theatre: "the zoom becomes an agent of decay, as objects ebb until they suffer a lethal loss of identity, gradually transmuting the visual field into a final extinguishing darkness." 9 For his part, Snow stated: "I was thinking of, planning for, a time monument in which the beauty and sadness of equivalence would be celebrated, thinking of, trying to, make a definite statement of pure film space and time, a balancing of 'illusion' and 'fact,' all about seeing. The space starts at the camera's (spectator's) eye, is in the air, then is on the screen, then is within the screen, (the mind). The film is a continuous zoom [...] a sine wave."10 Elizabeth Legge deemed the piece a "room zoom" that at times featured superimposed images in a slight double vision, as if the camera lens or projector were malfunctioning, as if our eyes were mis-seeing. Snow further related Wavelength to acid, like a drug forming states of consciousness in the mind-space. ${ }^{11}$ Strobing visuals and aliasing white waves stressed misidentifications of signal frequencies, introducing distortions or errors that preformed a random distribution of frequency and amplitude. ${ }^{12}$ Errors, interruptions, inconsistencies, and impediments to the senses by deprivation or excess led to blindness and mishearing. Gaps and intervals maintained a setting-apart of the senses, of sense. Synthetic coherency was discarded in favour of synthetic autism entrenched in the separation of

8 Lucy R. Lippard, “Perverse Perspectives,” Art International 11, no. 3 (1967): 28-33.

9 Julia Kristeva, "Le Théâtre moderne n'a pas lieu," 34/44: Cahiers de recherche des sciences des textes et documents 3 (1977): 13-16, quoted in Elizabeth M. Legge, Michael Snow: Wavelength (London: Afterall Books, 2009), 77.

10 Michael Snow, quoted in Legge, Michael Snow, 1-2.

11 Legge, 7, 25.

12 Legge associates the film with the acid guru Timothy Leary's crypto-visions of the "trip" described only a year earlier in Playboy, where Leary argued that they precede the sense of being alone in a dead impersonal world. Timothy Leary, "She Comes in Colors," Playboy 153 (September 1966), reprinted in Timothy Leary, The Politics of Ecstasy, repr. ed. (London: Paladin, 1972), 125. 
the performing heterogeneous senses. And yet, as Thierry de Duve noted, the experience of a blind spot enhances reflexivity (a lapse to which we will return, for it might be the very syncopation upon which everything is contingent). ${ }^{13}$ Snow's 45 -minute room zoom preformed the systematic abstraction of a perspectival construction of psychophysiological space. The problem raised in the difference between the two had already been stressed in Erwin Panofsky's Perspective as a Symbolic Form (192425), where he strikingly notes: "Visual space and tactical space [Tastraum, i.e., touch room] are both anisotropic and unhomogeneous in contrast to the metric space of Euclidean geometry.” He then turns to Ernst Cassirer, stating: “The main directions of organization-before-behind, above-below, right-left-are dissimilar in both physiological spaces.”"14 For Panofsky, the perception of space was contingent on sense perception. Tactile spaces were different from visual spaces since hapticity yields multi-directional aggregates that do not adhere to a unified oriented space. When the physiological sense-that is, the evidence of the eyes and ears, as seen in the cases above-was dislocated from its position of origin, or stressed under misalignment or excessive incitements, or posed between organised geometry and the world, blind spots and mishearing postponed the synthesis of this dissimilar physiological evidence, thus dispersing perception in suspension.

In what follows, I will focus on the weak relations between sight and touch dramatised in Robert Morris's series Blind Time Drawings. These works problematise our common understandings of perception by employing an aesthetic synthesis that grants primacy to the sense of touch while frustrating the clarity of vision as an organising mode of perception. They lure the spectator into the practice of the blind spot, the gaps between the separated senses, the fissures amidst the faculties and the erection of a quasi-transcendental apprehension. I will return to this uncanny phrase "quasi-transcendental" as it derives from sense perception and sensory production on the one hand, but is connected to the transcendence of the blind spot on the other. The drawings enact a gap between sightless touch, the pressing body, and the image to come. Morris begins by blindfolding his eyes. He then makes repetitive marks on a piece of paper. Each drawing is accompanied by or paired with an event score. His instructions, furthermore, furnish a temporal estimation for each performative drawing. He often calls this activity of timing-that is, the production of each work-“lapsed time” and "time error.” The scores frame Morris’s activity in relation

13 For Thierry de Duve, Snow marked the postmodern shattered trust in a unified self. He asked: "Given that the unity of experience is shattered, what can be done that is epistemologically enlightening and aesthetically stimulating?” The answer, he argued, is to identify the fragments that were once unified as the conditions of experience that must be freed. He suggests that Snow takes on this Modernist strategy of unconcealment and autonomy of parts to produce pleasure. See Thierry de Duve, "Michael Snow: The Deictics of Experience and Beyond," Parachute 78 (April-June, 1995): 28-29.

14 Erwin Panofsky, Perspective as Symbolic Form, trans. Christopher S. Wood, new ed. (New York: Zone Books, 1991), 30, 77. 
to an estimated time (linear time, clock time). The activities accordingly lapse out of chronos (chronological time) to disclose inapt discords.

\section{Blindfolded}

The artist activates the body in withdrawal. He suggests a base materialism that adheres to nothing but the proximities of skins and surfaces blindly touching their exposed externalities. His finger movements, their weight, pressure, velocity, and cadence, perpetually desire an image that can only be achieved in discreteness, in delay, posed in externality. This excessive movement requires some consideration. How does the movement towards coming-into-form (sense) adhere to the separation of the senses, to the impediment of sight? When pressure touches upon a surface, does its mark trace a blind image of its own exposition? Does it make sense through synthesis, or does the blind operation maintain a delay? How does suspension play out between gathering (synthesis) and aisthēsis? In a sightless world, does art refer only to itself, to its sensible senses, to its own causation? In a world without images, does touch refer only to touch? Does it touch touch? The technē of the world? In Anti Form, Morris writes: "The focus on matter and gravity as means, results in forms that were not projected in advance" (Anti Form, Artforum, April 1968). The Blind Time Drawings maintain suspension, a blacked-out movement towards an uncertain vestige. They inquire about our relation to time performed as a discontinuous passage of the ongoing creative nature of pressure. They render time as a lapse, a proposition of syncopation in the heterogeneity of times. If this trajectory makes sense, how may we think about the image if it is nothing but a trace; a weak, passive form drifting amidst the effects of the touching senses?

Blind Time Drawings spans from 1973 to the present, amounting to approximately several hundred pieces, the series is divided into six sub-series and some additional works. ${ }^{15}$ The first drawing, Blind Time I (Fig. 12) comprises a title, date, medium, paper size, collection, event score, and drawing. The drawing presents a vestige of Morris's graphite traces of finger marks springing from the bottom up. The movement of the fingers follows a singular framework of instructions that includes the suspension of the gaze, an estimated time for the activity, a score for haptic movement, and finally a measure of the activity of drawing in real time; that is, in numeral/chronological time. The first score instructs:

With eyes closed, graphite on the hands and estimating a lapsed time of 3 minutes, both hands attempt to descend the page with identical touching motions in an effort to keep to an even vertical column of touches. Time estimation error: +8 seconds.

15 Jean-Pierre Criqui, “Drawing from the Heart of Darkness: Robert Morris' Blind Time," in Blind Time Drawings, 1973-2000, ed. Jean-Pierre Criqui (Prato: Centro per l'Arte Contemporanea Luigi Pecci, 2005), 11. 


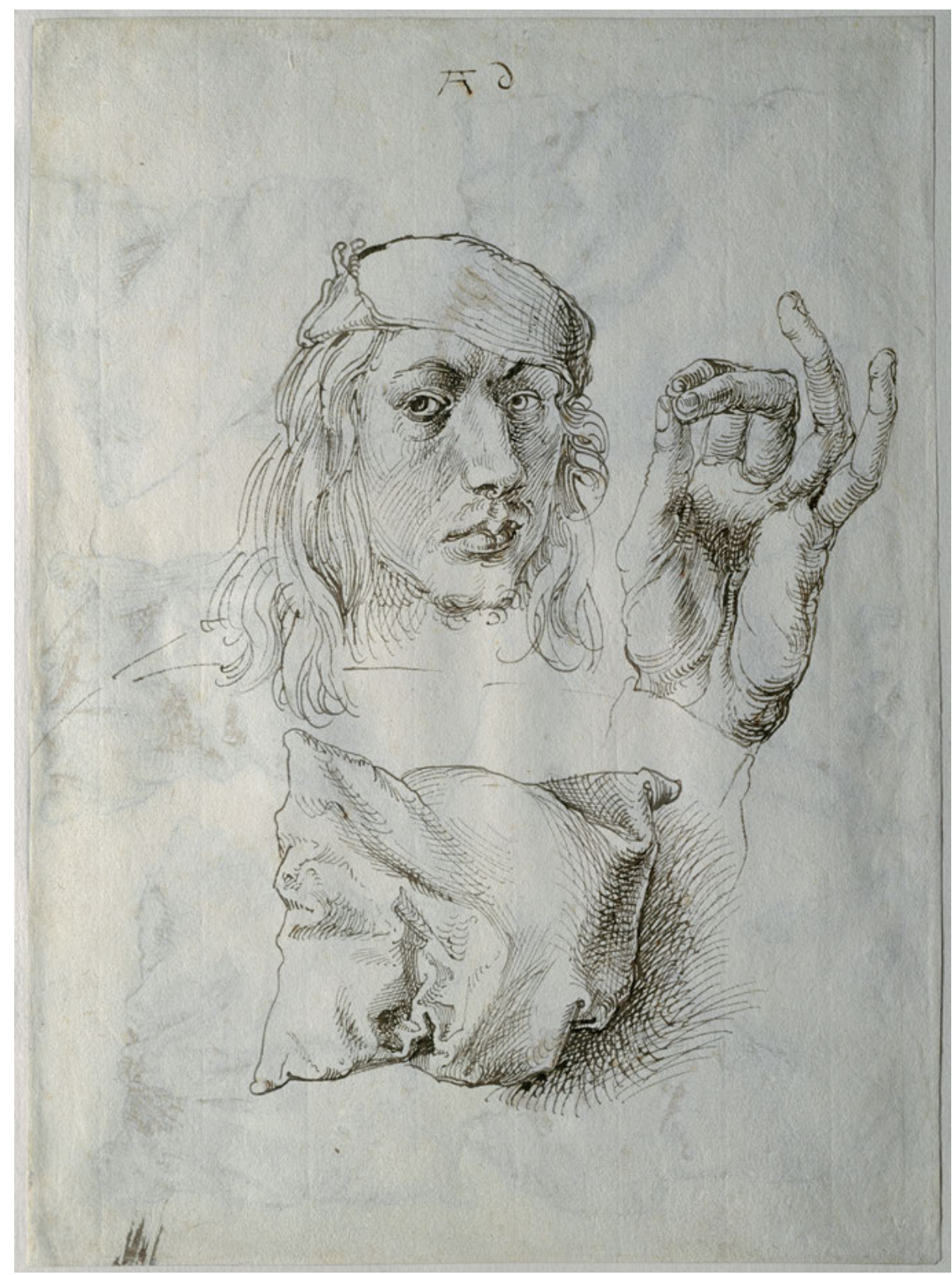

Fig. 13: Albrecht Dürer, Self-portrait, Study of a Hand and a Pillow (recto), 1493, pen and brown ink, $27.8 \times 20.2 \mathrm{~cm}$. Robert Lehman Collection, 1975 (1975.1.862). Photographed by Schecter Lee, The Metropolitan Museum of Art. Image source: Art Resource, New York.

With his eyes closed, Morris begins in withdrawal. The first withdrawal is from mimesis; from forms that were not projected in advance. The second withdrawal is from self-imitation. The score and materials serve to set the conditions for the activ- 
ity. A model is suspended in thought at the time of performing the act of drawing, in the moment of its coming-into-form. In each singular piece, Morris repeats the act of notation thrice: once in preforming his own instructions, then in the double performance of the hands "with identical touching motions," simultaneously pressing the surface, opening infinitesimal gaps in the cadence, weight, and vectors of each movement. Each time, each expression is different. The third is a withdrawal from painting. The drawing is not a painting. "I quit painting," Morris declared, "for a particular reason-certain problems I couldn't solve. There was a kind of ontological character to painting I could not accept. Because on the one hand you were involved in some activity, on the other hand you ended up with an object." ${ }^{16}$ By hindering a coherent, significant object, Morris offers the remainder as the vestigial form of a withdrawal from the sense of painting; a passage of hand-gestures passing through the limits of the cutting frame. Devoid of object, pictorial activity retreats from the pregiven ground of painting, the skeleton support of symbolic order, to form inter-relations contingent upon haptic weight.

The fourth withdrawal is from the knowing, conscious hands of the painter. By painting with the palm of his hands, Morris makes a portrait of his hands. When painters paint hands, they usually depict the dorsum, their upper side: Leonardo's caressing hands, Michelangelo's signifying or concealing hands, Andrea del Sarto's entangled hands, Watteau's open hands, the hands of the transfiguration, Dürer's praying hands, the pointing hand, the hands of God the Father, of the Emperor, holding hands, fists. Dürer's Self-portrait, Study of a Hand and a Pillow (1493) depicts the artist's palm, his fingers at once touch themselves and point up to his signature monogram. This self-referentiality presents the artist as creator. Creator of his own image. The painter as creator. Dürer's self-portrait as the divine creator. Morris does not depict the hands in their mediated likeness, but instead captures the finger-prints, his distinct self in intimate flesh. His gestures are singular each time. One after another, they are painterly discrete events. For Morris, these imprints mark a way out of the pictorial object while maintaining temporal suspension.

\section{Knowing/Pressing}

Morris shifts from the order of knowledge, language and signification to the ontology of touch. Marking imprints contingent upon the event score is a performative act which is a touch at the very foundation of painting. By replacing sight with touch, Morris considers the problem of how to make a pictorial mark devoid of connection to a grounding referent, and with no expressive overtones. If the pictorial mark is but

16 Transcript of an interview conducted between Thomas Krens and Robert Morris dated 13 December 1978. See Thomas Krens, “The Triumph of Entropy," in Robert Morris: The Mind/Body Problem (New York: Solomon R. Guggenheim Foundation, 1994), xix. See also Criqui, "Drawing from the Heart of Darkness," 11-12. 
an imprint contingent upon eyeless pressing palms, it differs from the diagrammatic face by inscribing an immediate surface-topography of the body. It is neither a representation, nor an inscription of a model or a face, but an ex-scription, that is, a becoming-other-than-itself in the event of an expressive gesture. The pressure of the weight of the body preexists the know-how of the practiced painter. The blind painter's gestures are expressive events that render their temporal traces as distancingfrom-self in its absolute strangeness. ${ }^{17}$ In The Vestige of Art, Nancy reminds us that "the word 'face' comes from the root that means "to pose, to set": to pose, present, expose without reference to anything. Here, without relation to anything that is an a priori substratum or an intelligible subject projecting forms. With the sole or the bottom of the foot [la plante du pied], we are in the domain of the flat, of the out-flat [l'ordre du plat et de l'à-plat], of horizontal extension without reference to vertical tension." 18 Nancy's footprint. Morris' palm. These transient imprints are not images of their creator's self-knowledge; they do not mark an identity but a transient event with an unnameable sense of the relations of physical organs.

When tending to the problem of the haptic body in Morris' work, Rosalind Krauss asks: "What is it like to be a body?"19 She argues that the experience of impact is that of resistance to an external material and has a definite telos as it "creates an awareness of the body as sheathing, isolating it as a kind of boundary that can be peeled away from the self and presented as pure corporeality.” Morris, influenced by Samuel Beckett, performs his transient self through pressure. Beckett's Unnamable (1953) is a score, a partitura, a play, posing a reflexive hapticity, a facticity, where touch touches upon the mind/body split, pressing bodily organs into self-awareness. "Of whom I know nothing... I know I am seated," says the stationary protagonist of Unnamable:

My hands on my knees, because of the pressure against my rump, against the soles of my feet, against the palms of my hands, against my knees. (Against my palms, the pressure is of my knees, against my knees of my palms, but what is it that presses against my rump, against the soles of my feet? I don’t know.) My spine is not supported. ${ }^{20}$

The passage is divided as a mirror image of itself. Beckett commences with questioning thought and his ability to know. He then positions his hands, his knees, his rump, the soles of his feet, the palms of his hands, and his knees. Now again, in rotation and inner-twists: palms, knees, knees palms, rump, feet. Note that Beckett

17 Jean-Luc Nancy, "Painting in the Grotto,” The Muses, trans. Peggy Kamuf (Stanford: Stanford University Press, 1996), 70.

18 Jean-Luc Nancy, “The Vestige of Art,” The Muses, trans. Peggy Kamuf (Stanford: Stanford University Press, 1996), 97.

19 Rosalind Krauss, "The Mind/Body Problem: Robert Morris in Series," Robert Morris: The Mind/ Body Problem (New York: Solomon R. Guggenheim Foundation, 1994), 10.

20 Samuel Beckett, The Unnamable (New York: Grove Press, 1958), 15. 
opens with knowing while he ends with feet; from top to bottom, from mind to body, from a vertical to a horizontal disparity of heterogeneous organs:

[un]Knowing

$\begin{array}{ll}\text { Knees } & \text { Palms } \\ \text { Rump } & \text { Knees } \\ \text { Feet } & \text { Knees } \\ \text { Palms } & \text { Palms } \\ \text { Knees } & \text { Rump } \\ & \text { Feet }\end{array}$

Beckett does not know his body; he feels the heterogeneity of the organs of a body. Knowing is positioned over and on a par with a dismembered body. The dispersed body is not only the failure of expression bent on the debility of language and the production of meaning; it is also the atemporal zone conditioning the text right from the start: "Where now? Who now? When now? Unquestioning. I, say I. Unbelieving. Questions, hypotheses [...]. Keep going, going on." ${ }^{21}$ Paul Davis related this decentred speaker to a "pre-Cartesian Unthinkable," a wonderer-self, an unnamable being who utters the Cartesian Cogito into self-annulment. ${ }^{22}$ "I seem to speak (it is not I) about me (it is not me)," Beckett writes, "What am I to do (What shall I do, what should I do?) in my situation? How proceed? By aporia pure and simple? Or by affirmations and negations invalidated as uttered [...]. (I should mention before going any further-any further on-that I say 'aporia' without knowing what it means)."23 The unhinged relations of the anthropomorphic organs do not, and cannot, constitute a body; they are unhinged twice. To recall Mladen Dolar's "Kafka's Voices," there is first the anastomotic voice performing the indeterminate interconnection between the corporeal and the symbolic. ${ }^{24}$ Dolar returns to Jacques Lacan's anastomosis in order to unhinge the voice from language. The chiasmic order of the separated organs now exists outside the known body. The undefinable relations posed by the dissected autonomous organs pose an aporia in the symbolic order. This aporia marks the paradoxical object of lack, the objet petit $a$, that manifests the drive of the incomplete symbolic order. ${ }^{25}$ For Slavoj Žižek this lack unhinges a

21 Beckett, The Unnamable, 1.

22 Paul Davies, Beckett and Eros: Death and Humanism (Basingstoke: Macmillan Press; New York:

St. Martin's Press, 2000), 48.

23 Beckett, The Unnamable, 1.

24 Mladen Dolar, “Kafka’s Voices,” in Lacan: Silent Partners, ed. Slavoj Žižek (London: Verso, 2003), 317.

25 Jacques Lacan, The Four Fundamental Concepts of Psychoanalysis, trans. Alan Sheridan (New York: W.W. Norton \& Company, 1978), 67-90. 
subject without subjectivity. ${ }^{26}$ The second unhinging is a materialisation of the Real, that is, of language, and the "literature of the unword" that creates a porous language. In Beckett's “German Letter” to Axel Kaun (July 1937), he suggests that the materiality of the word should be "dissolved [...], devoured by great black pauses [...], linking unfathomable abysses."27

The porous body is always plural; it performs itself through a perpetual coming together and falling apart that maintains the heterogeneity of organs, zones, names. In Beckett, such zoning marks the split of a body and a mind, and a further double split of the mind into zones and the body into autonomous corporeal organs. Murphy, Beckett's protagonist in the 1938 novel, performs the mind/body dichotomy as he "felt himself split in two, a body and a mind. They had intercourse apparently, otherwise he could not have known that they had anything in common. But he felt his mind to be bodytight and did not understand through what channel the intercourse was affected, nor how the experiences came to overlap." ${ }^{28}$ Later on, Murphy's mind splits into three zones: the first is the zone of "light," the second is that of "half-light," and the third is the dark zone of a "flux of forms" that constantly materialise and dematerialise. ${ }^{29}$

The sexual nature of Beckett's mind/body split re-emerges in the passageways between the zoned organs of the mind and the body. They characterise the mental activity of self-reflection as the sensual contact of erogenous zones, those internal tactilities aroused in and in-between the limits of Didier Anzieu's psychoanalysis of the skin-ego. Although Anzieu is considered Lacan's greatest critic, his concepts of the skin-ego and the psychic envelope offer a non-dualistic and non-deterministic thinking of subjectivity as "completely psychic, utterly somatic, essentially intersubjective and intercorporeal, constantly changing." 30 He critiques Lacan's linguistic model of the unconscious, claiming that it produces an analysis of signifiers as an

26 Žižek returns to Jonathan Boulter's observation of Beckett's Texts splitting the voice and the body not only to dismantle the physical body, but to stage its comeback unhinged from subjectivity. See Slavoj Žižek, Disparities (London: Bloomsbury Academic, 2016), 468-69; Jonathan Boulter, "Does Mourning Require a Subject?” Modern Fiction Studies 50, no. 2 (Summer 2004), 333-34.

27 Ruby Cohn, A Beckett Canon (Ann Arbor: University of Michigan Press, 2001), 88-89.

28 Samuel Beckett, Murphy, ed. J.C.C. Mays, new ed. (London: Faber and Faber, 2009 ), 70.

29 Beckett, 63-64.

30 Marc Lafrance, "Skin and the Self: Cultural Theory and the Anglo-American Psychoanalysis," Body and Society 15, no. 3 (2009): 19. Naomi Segal demonstrates the connections and closeness of interpretation in Didier Anzieu and Beckett, in particular through Anzieu's writings regarding selfanalysis and creativity, A Skin for Thought: Interviews with Gilbert Tarrab on Psychology and Psychoanalysis (1990; see the translation by Daphne Nash Briggs [New York: Routledge, 2018]) and The SkinEgo (1995; see the translation by Naomi Segal [London: Karnac, 2016]). See Naomi Segal, Consensuality: Didier Anzieu, Gender and the Sense of Touch (Amsterdam and New York: Rodopi, 2009). On Anzieu amidst his contemporary thinkers, see Marc Lafrance, "From the Skin Ego to the Psychic Envelope: An Introduction to the Work of Didier Anzieu," in Skin, Culture and Psychoanalysis, ed. Sheila L. Cavanagh, Angela Failler, and Rachel Alpha Johnston Hurst (New York: Palgrave Macmillan, 2013), $16-17$. 
exercise in linguistic virtuosity determined by preconceived knowledge. Anzieu charges Lacan with a fanciful formal logic that is not only far removed from psychoanalytic therapeutic purposiveness, but also a dangerous practice that may result in the patient's collapse. ${ }^{31}$ Seeing himself as profoundly Freudian, Anzieu rejected the hypothesis that the unconscious is structured like a language and instead claimed that the unconscious forms through the sensual experience of the body. ${ }^{32}$ As early as 1911, Freud developed his model of "primary processes" as the biological and psychological activity of the pleasure principle which precedes thought, advancing a pre-ego phase that does not intuit space and time or differentiate the dialectic dualism between inside/outside, subject/object. ${ }^{33}$ In fact, Anzieu argued that the bodyego is a skin-ego that functions both as a binding force and as a boundary touched by containment, protection, and inscription. ${ }^{34}$ Here, the skin becomes the locus of a haptic intersensorial relation, which connects sensations and organises them such that they "stand out as figures against the original background formed by the tactile envelope: this is the Skin Ego's function of intersensoriality, which leads to the creation of 'common sense'... whose basic reference is always to the sense of touch." 35 The tactile nature of intersensoriality preceding any original background is propelled by desire and pleasure. Anzieu follows Freud's pleasure of the skin in the tangible play of erogenous zones facilitating auto-eroticism and sexualisation. ${ }^{36}$ By replacing the already structured Lacanian linguistic model of self-reflection with a psychic-somatic one, the experience of the senses and their dialogic relations brings us back to Beckett's haptic Unnamable and Morris's Blind Time Drawings, delineated as a body/ mind, organ/sense, relation carving paths amidst the separated senses, to now consider the principle of plurality contingent upon the facticity of the tangible.

31 Anzieu, A Skin for Thought, 35-37. See also Anzieu, "Contre Lacan” (1968), in Didier Anzieu, Psychanalyser, ed. René Kaës (Paris: Dunod, 2000), 179-85.

32 'I myself would oppose the formula: 'the unconscious is structured like a language' with a formulation that is implicit in Freud: 'the unconscious is the body.' The unconscious seems to me to be structured like the body [...] as a source of the first sensory-motor experiences, the first communications, and the oppositions that relate to the very basis of perception and thought." See, Anzieu, A Skin for Thought, 43.

33 Sigmund Freud, "Formulations on the Two Principles of Mental Functioning," in The Standard Edition of the Complete Psychological Works of Sigmund Freud: Volume 12 (1911-1913): The Case of Schreber, Papers on Technique and Other Works, ed. James Strachey et al. (London: Hogarth Press, 1958), 218-26.

34 Didier Anzieu, "Functions of the Skin-Ego," in Reading French Psychoanalysis, ed. Dana BirkstedBreen, Sara Flanders, and Alain Gibeault (London and New York: Routledge, 2010), 479.

35 Anzieu, "Functions of the Skin-Ego," 484.

36 Sigmund Freud, "Three Essays on the Theory of Sexuality," in The Standard Edition of the Complete Psychological Works of Sigmund Freud, Volume 7 (1901-1905): A Case of Hysteria, Three Essays on Sexuality and Other Works, ed. James Strachey (London: The Hogarth Press, 1953), 125-245. 


\section{Somatic Actions}

In 1991, Morris crystallised his inquiry of the haptic/cognitive relations. For the subseries Blind Time IV, he added excerpts from the writings of Donald Davidson, an American philosopher of the mind, language, and action, to his blind time event scores. Blind Time IV (Drawing with Davidson, 1991) is composed of two excerpts, the first staging the artist's cognitive activity and the movement of the hands, the second is a citation from Davidson's essay "Agency" (1971), ${ }^{37}$ and a graphite drawing.

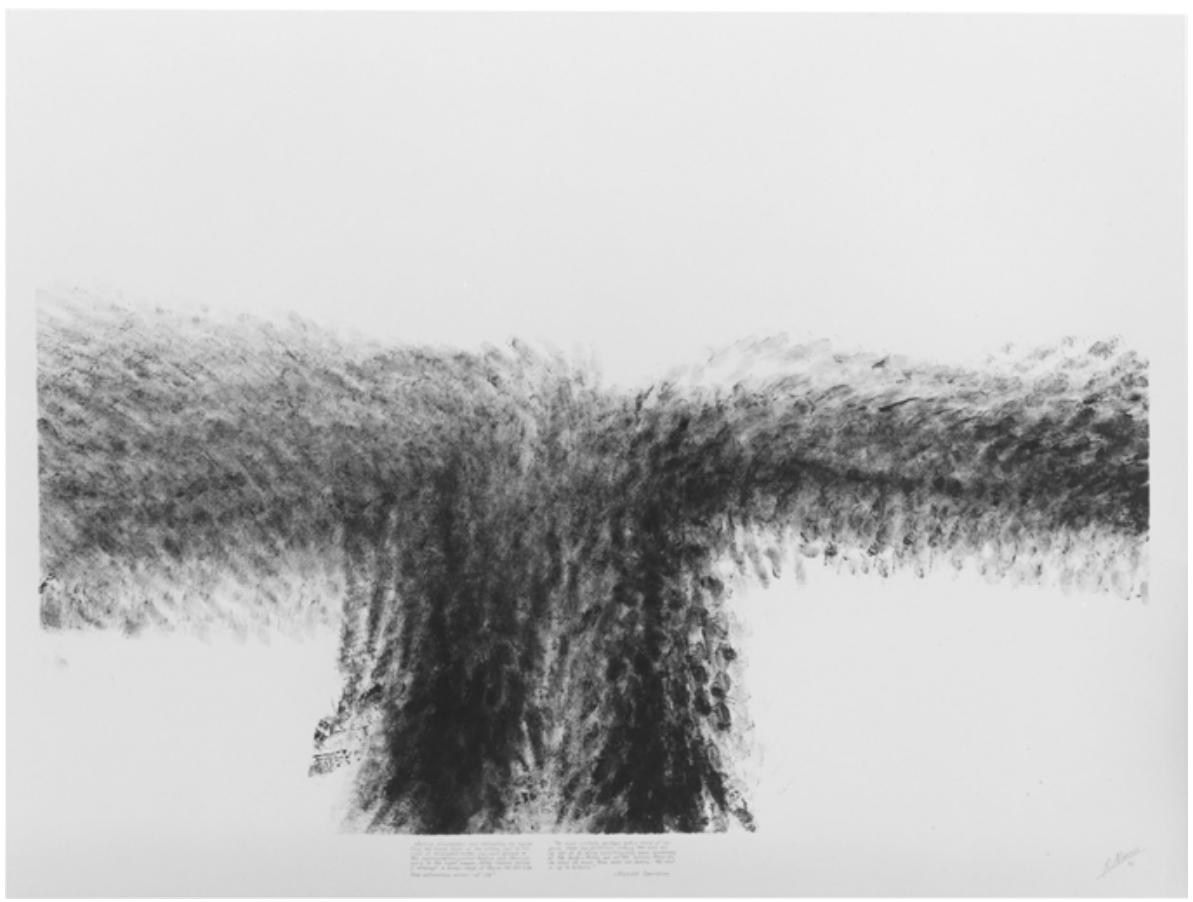

Fig. 14: Robert Morris, Blind Time IV (Drawing with Davidson), 1991, graphite on paper, $96.5 \times 127 \mathrm{~cm}$. (C) Robert Morris / Artists Rights Society (ARS), New York (Courtesy of Castelli Gallery).

Working blindfolded and estimating the lapsed time the hands begin at the bottom, just to the right of estimated center and work upward to the estimated horizontal median and then outward to the right margin. After several passes I attempt a mirror image of this on the left side.

Time estimation error:-2’:08““

We must conclude, perhaps with a shock of surprise, that our primitive actions, the ones we do not do by doing something else, mere movements of the body-these are all the actions there are. We never do more than move our bodies: the rest is up to nature.

37 Donald Davidson, “Agency," in Donald Davidson: Essays on Actions and Events (Oxford: Clarendon Press, 2001), 51. 
By 1993, he had published a text in which he contemplated his engagement with the scripts entitled "Writing with Davidson: Some Afterthoughts after Doing Blind Time IV: Drawing with Davidson." ${ }^{38}$ Morris opens his commentary by asking: "What were Donald Davidson's writings doing in Morris's Blind Time Drawings?" 39 In order to unearth the reason for his engagement with Davidson, as Morris himself encourages us to do, we should consider his relationship to Davidson's ideas about intentions, actions, reasons, causes, beliefs, and desires. Kenneth Surin carefully illuminated these connections while adding a particular concern with proprioception and the haptic operation of Morris's nonrepresentational Blind Time Drawings. He follows Brian O'Shaughnessy's claim that the sense of touch depends on proprioception as a causal relation between the touched object and the sense perception of the touching body, hence integrating haptic perception with bodily awareness. ${ }^{40}$ Surin sees Morris's use of his sense of touch as a proprioceptive mode contingent on bodily awareness as a kind of projective mapping that constitutes nonvisual analogue relations "that make up the ordered and intelligible experience of (visual) appearance." ${ }^{\text {"1 }}$ For Surin, Morris's haptic procedures lead to a kind of visual understanding. While I agree with Surin's general trajectory of bypassing the rational agent, Morris's blind hapticity seems to show disdain for understandable auto-articulation. His experimentation with somatic knowledge abrogates visual and linguistic construal altogether. "Sightless repetitions echo a kind of laughter not permitted in light. Not every dark itch can be scratched in daylight," wrote Morris. "It would not be inconsistent to ascribe a certain bravado to method [...], not to mention a contempt for the ironclad primacy of the visual, that reification of the seen promoted to a self-serving ontology that the "visual arts' never tires of asserting," and later on, "We always assume (theorize) a wholeness of the visual." ${ }^{42}$ Hence, if Morris abrogated vision (as sensual sense and as knowledge), what was left was an agent of action stripped of reasoning, but one for whom there is no difference between action and cause. Davidson's "primitive actions" propose a mode of activity that includes all bodily movements. In Agency, Davidson proposes to interpret the idea of bodily movements as primitive actions. These movements cannot be analysed according to causal relations

38 In summer 1993, Critical Inquiry published two back-to-back articles concerned with Blind Time Drawings: Donald Davidson, “The Third Man,” Critical Inquiry 19, no. 4 (1993): 607-16, and Robert Morris, "Writing with Davidson: Some Afterthoughts after Doing Blind Time IV: Drawing with Davidson,” Critical Inquiry 19, no. 4 (1993): 617-27.

39 Morris, "Writing with Davidson," 617.

40 To bridge the gap between haptic perception and intelligible awareness, Surin turns to Michael Martin's assertion that touch utilises the body's sense-field through proprioception in order to incorporate the projective mapping of an object. See Kenneth Surin, “Getting the Picture: Donald Davidson on Robert Morris's Blind Time Drawings IV (Drawing with Davidson),” The South Atlantic Quarterly 101, no. 1 (2002): 152-64, 168-69.

41 Surin, 155.

42 Morris, "Writing with Davidson,” 620, 624. 
or the first attribution of agency, nor do they require an intentional description. ${ }^{43}$ If we do find such relations between agent and action, they will be of a descriptive nature, describing the consequences of the action. "Knowledge that an action $a$ has a certain upshot allows us to describe the agent as the cause of that upshot, but this is merely a convenient way of redescribing $a$, [...]. Causality allows us to redescribe actions [...], but yields no analysis of agency." ${ }^{44}$ Davidson concludes that the relation between a person and an event takes place only when it is his action that is independent of how the terms of relations are described. In fact, the relation between agent and action can only be described after-act, after-thought. In the real-time performative act, the relation between agent and action is a blind difference.

Within the philosophical labyrinth encompassing Morris's art, we stumble into blind and dark turning points that cannot be explained. Morris characterises the drawings as obsessive, sightless reiterations that reject vision in favour of somatic actions devoid of psychophysical law. In "Writing with Davidson," Morris asks: "Might it not be more profitable to regard the act of 'drawing blind' (as well as that of affixing Davidson's texts-perhaps as a kind of libretto that Morris sang as he worked blind) as operating in that economy of an excess [of transgression] which is the very ground of the metaphorical?" 45 The latter is the only mode we may find in Davidson that cannot be decoded or explained.

\section{The Haptic Interval}

What does Morris mean when he suggests that it would be more profitable to regard the act of "drawing blind" as operating in the economy of excess? In footnote 8 of "Writing with Davidson," Morris turns to Lacan's objet $a$ as the unattainable image of desire. In fact, he specifically refers to Lacan's lecture entitled "Anamorphosis" to stress how the impossible image of drawing blind touches upon "a sort of ultimate limit of identification" that stirs "a self-portrait in which the subject will see himself as he cannot see himself [...] in which his own nullity appears to him." ${ }^{46}$ Lacan's "Anamorphosis" shows how the emergence of the subject from the reflecting reflection of the structure of the gaze is contingent upon an internal split in the subject induced by objet $a$. Placing the unimaginable interval as the heart of the self-reflecting seeing subject, Lacan induces the framework of the fundamental drives through the movement of desire. ${ }^{47}$ Stirring the function of lack, Morris's painterly actions dis-

43 Davidson, “Agency,” 49.

44 Davidson, 60.

45 Morris, "Writing with Davidson," 627.

46 Morris, 622-23.

47 In 1964, Lacan gave a series of lectures at the École Normale Supérieure (Lectures 8 and 9, 26 February 1964) entitled "The Split Between the Eye and the Gaze" and "Anamorphosis," which addressed the question of how we can situate the conscious from the perspective of the unconscious. 
charge their operative identity via blindness, thus making blindness a syncopated impediment at the centre of the creative act. The exposition of these self-relations is at once contingent on the disorder and delay of the sense of sight and on sense as meaning. Thereafter, a question is raised regarding the activity of the haptic painter. The order of the gaze now practised by hapticity may seem to offer an immediate solution to the problematic relations Morris finds between the activity of painting and its purpose in creating an object: "There was a kind of ontological character to painting I could not accept. Because on the one hand you were involved in some activity, on the other hand you ended up with an object." ${ }^{48}$ Here, "object" refers first and foremost to the production of coherent concepts, and the material body designated as the painting is of a second order. How does haptic activity relate to the creativity of painting? How does it differ from the production of clear images or concepts? And how may we think of touch in relation to sightless activity?

In the opening chapter of The Muses, "Why Are There Several Arts, Not Just One?", Jean-Luc Nancy seeks to expose the manner of creation, or what he calls the sense of the world, through the suspended movement of touch. When attending to the question of the heterogeneity of the senses and the arts, Nancy presents the problem of sense, which on the one hand implies the somatic-that is, sensory-dimension of aesthetic experience and on the other relates to the sense of the world which for him is creation's manner of operation. The question of creation is the question exposing the manner, or mode, of the arts. Such exposition does not know its own becoming; therefore, Nancy stresses the characteristics of non-knowledge. He argues that "art disengages the senses from signification [...], and that is what we call [...] the sense of being external to signification [...] what one might just as correctly call the 'sense of the world' [...] as suspension of signification." ${ }^{49}$ The withdrawal from signification includes untying the sensory apparatus from the production of meaning while maintaining their unhinged relation in suspension. In such a state, the senses are separated from the mind and therefore cannot comprehensively grasp an enunciated concept. The sense of creation is removed from signification in order to expose its own manner of self-relation. Suspension is again introduced

\footnotetext{
Both his question and his argument utilised a performance of pictorial geometrical perspective, splitting the eye from the gaze, playing with the triangular form, doubling it, turning it around, and overlapping its scheme, to create the chiasmic structure. Subdued to the function of desire within the operation of the gaze, the emergence of the subject was formed in the ungraspable, illusionary consciousness of seeing itself seeing itself; I saw myself seeing myself; I see myself seeing myself. This is a bipolar reflexive relation that no longer allows the appropriation of self by reflection; in fact, it annihilates the subject geometrical constitution in favor of the movement of lack and desire. See Lacan, The Four Fundamental Concepts of Psychoanalysis, 67-90.

48 Krens, "The Triumph of Entropy," xix; see n. 17 above.

49 Jean-Luc Nancy, “Why Are There Several Arts, Not Just One?”, in The Muses, trans. Peggy Kamuf (Stanford: Stanford University Press, 1996), 22. On the problem of signification in Nancy, see Charles Shepherdson, “Aesthetic 'Sense' in Kant and Nancy,” New Literary History 48, no. 2 (2017), $197-221$.
} 
as an unbridged interval maintaining the separation of the senses, as well as the separation of each sense from its own self-awareness.

Nancy then poses the exposition of self-relation as a haptic operation that adheres to the movement of a hyletic circle, which is an uncountable and raw haptic movement. Nancy's hyletic circle follows the order of self-relation we find in Lacan, Anzieu, but also in Freud. He seems to weave Anzieu's haptic motive with Lacan's formal mechanism, that is, his chiasmic screwing hyletic circle. If Lacan offers the relation of consciousness and representation by tending to the reflective order of "I see myself seeing myself," Nancy offers touch as it "feels itself feeling itself." 50 From Freud, Nancy imports the movement of the erotogenic zones as a haptic movement of desire-the Verlust. He elaborates on how such tactility touches itself. Sense senses itself by touching as touch touches touch. Touch touches on nothing but itself while it syncopates itself in material plurality. The suspended interval at the heart of the hyletic circle is the auto-heterology of touch. It is the spacing and the difference of zones and a relation-to-self:

Touch itself-inasmuch as it is a sense and consequently inasmuch as it feels itself feeling, or more than that, inasmuch as it feels itself feeling itself, since it only touches by touching also itself, touched by what it touches and because it touches-touch presents the proper moment of sensuous exteriority; it presents it as such and as sensuous. What makes for touch is "this interruption, which constitutes the touch of the self-touching, touch as self-touching." Touch is the interval and the heterogeneity of touch. Touch is proximate distance. It makes one sense what makes one sense (what it is to sense): the proximity of the distant, the approximation of the intimate. ${ }^{51}$

Granting primacy to touch, Nancy returns to Aristotle's heterogeneity of the senses, and yet differs from him by offering touch not only as the sense that encompasses all the other senses (sensus communis/koine aisthēsis), but as a condition for all sentient life. In Aristotle, touch occurs at the liminal difference between interior and exterior. Pascal Massie dwells on the double movement of the sense of touch, exhibiting the duality of a proper and common function by pointing simultaneously to the object of sensation and the sensing of the object. ${ }^{52}$ Yet this beguiling sensual sense and a gathering synthetic sense appear simultaneously empirical and transcendental. Daniel Heller-Roazen argues that for Aristotle, "the significance of the primary sensation [...] lies not in its proximity to the modern notion of consciousness but in its removal from it." ${ }^{53}$ What he offers as sense perception and self-awareness are not forms of

50 Lacan, “Anamorphosis,” The Four Fundamental Concepts of Psychoanalysis, 80; Nancy, "Why Are There Several Arts, Not Just One?”, 17.

51 Nancy, The Muses, 29.

52 Pascal Massie, “Touching, Thinking, Being: The Sense of Touch in Aristotle's De anima and Its Implications,” Minerva: An Internet Journal of Philosophy 17 (2013): 90.

53 Daniel Heller-Roazen, The Inner Touch: Archaeology of a Sensation, paperback ed. (New York: Zone Books, 2009), 40. Pavel Gregoric maintains a similar sensual route, claiming that the common 
cognition or awareness, but rather forms of sensation. Mark Shiffman and T.K. Johansen argue that the physical and the mental are an actualisation of sense perception and sensibility. ${ }^{54}$

For Aristotle, the common faculty sensing one's very feeling is most manifest in tactile sensations. Nancy carries out a double movement: first, the empirical puttingto-work and then the logos of sense pronouncing itself. ${ }^{55}$ This is the tactile reflexivity of sensation whereby the senses disclose not only what they are sensing, but also that they are sensing. ${ }^{56}$ Here, Nancy pays attention to the haptic interval, which he poses at the chiasmic intersection of the blind spot. The blind haptic interval is an undecidable syncopation which comprises and energises the hyletic circle. It is a cancelling out and a withdrawal on which everything is contingent because the movement of the chiasm requires an incommensurable desert, a deserted withdrawal, that maintains a spiral movement, an élan, which is perpetually the same, yet always in difference.

Nancy opens this impossible dialectic into a manner of withdrawing from representation, from absolute knowledge, which constitutes a syncopated synthesis of the undecided self: "It undoes itself," Nancy writes, "and it constitutes itself, fissures itself in the very gesture and instant in which it overcomes, fixes, and effaces its features." ${ }^{57}$ As such, "it is the art." ${ }^{58}$ That is, it is the art of uncovering the reciprocal

sense, for example, is identified with the sense of touch as an empirical sense of perception; see Pavel Gregoric, Aristotle on the Common Sense (Oxford: Oxford University Press, 2007).

54 Aristotle, De anima, ed. Mark Shiffman (Newburyport, MA: Focus Publishing, 2010), 22-23, and T.K. Johansen, Aristotle on the Sense-Organs (Cambridge: Cambridge University Press, 1997), 288-90. Although I will not address the empirical and transcendental split, this trajectory may be challenged, as seen in Aristotle: "While in respect of all the other senses we fall below many species of animals, in respect of touch we far excel all other species in exactness of discrimination. That is why man is the most intelligent (phronimōtaton) of all animals. This is confirmed by the fact that it is to differences in the organ of touch and to nothing else that the differences between man and man in respect of natural endowment are due;" see On the Soul, 421a20-25, in The Complete Works of Aristotle, ed. Jonathan Barnes (Princeton: Princeton University Press, 1984), 1:670.

55 For Aristotle, touch is conceived as the utmost essential sense among perceptive beings, since "without touch there can be no other sense." See On the Soul $435 \mathrm{a} 4$ (1:692). The senses are also interdependent on touch, since they "no doubt, perceive by contact." See $435 \mathrm{a} 19$ (1:691); however, touch is an independent sense: "There is one sense function, and the controlling sensory organ is one, though differing as a faculty of perception in relation to each genus, e.g., sounds or colour; and since this subsists with in association chiefly with the faculty of touch (for this can exist apart from all the other organs of sense, but none of them can exist apart from it-a subject of which we have treated in our speculations concerning the soul);” see Aristotle, On Sleep 455a2025 (in The Complete Works of Aristotle, 1:723).

56 And again, but on a different order, "And thought thinks itself because it shares the nature of the object of thought; for it becomes an object of thought in coming into contact with and thinking its objects, so that thought and object of thought are the same." See Metaphysics 1072b20-21 (The Complete Works of Aristotle, 2:1695).

57 Jean-Luc Nancy, The Discourse of the Syncope: Logodaedalus, trans. Saul Anton (Stanford: Stanford University Press, 2008), 10. 
relations of understanding and imagination in a given presentation. Thus art, for Nancy, is the exposition of its accord and discord of appearance.

\section{Lapsed Time}

Morris's Blind Time III (1985) performs the following event score in iron oxide on paper:

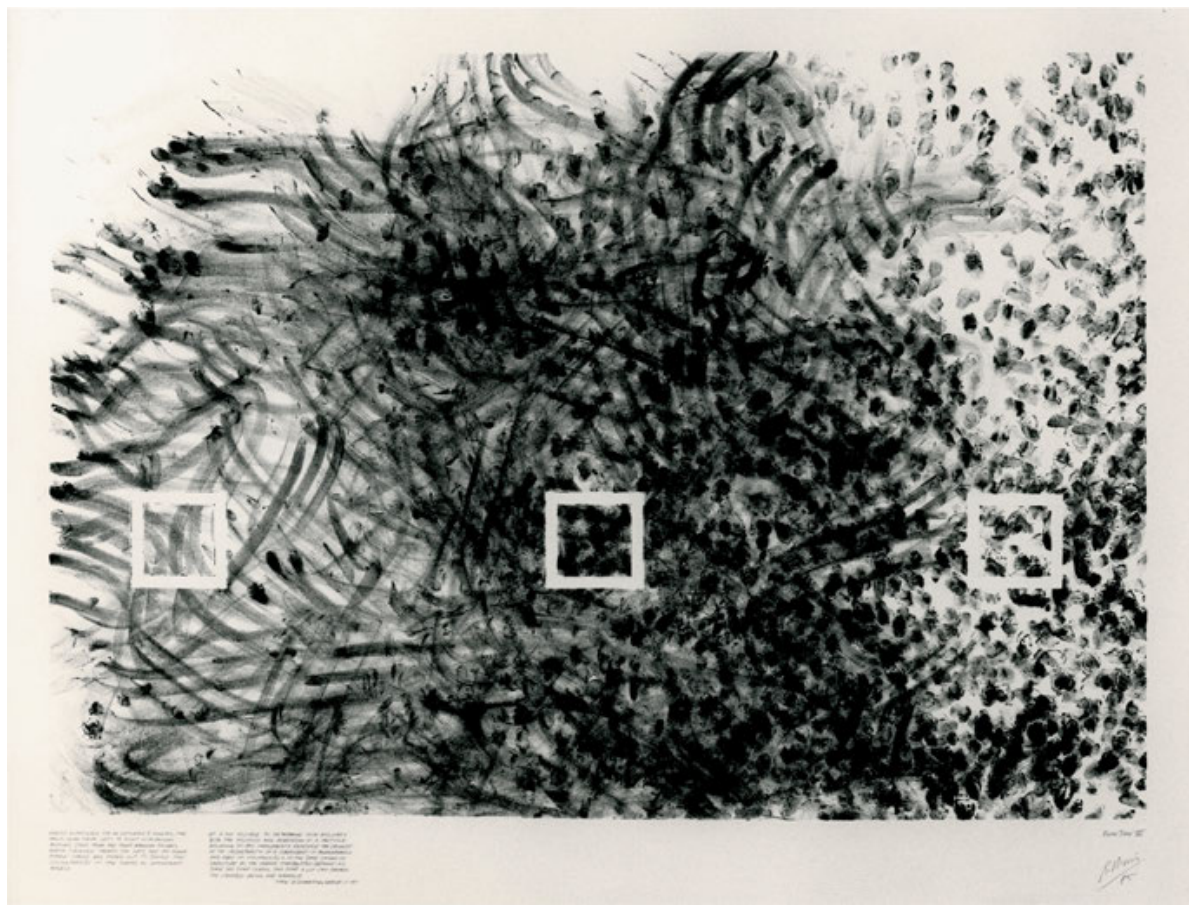

Fig. 15: Robert Morris, Blind Time III, 1985, iron oxide on paper, $96.5 \times 127 \mathrm{~cm}$. (C) Robert Morris / Artists Rights Society (ARS), New York (Courtesy of Castelli Gallery).

Working blindfolded for an estimated 5 minutes, the hands work from left to right with random motions. Then from the right random touches, which converge toward the left, are put down (three spaces are taped out to sample the discreetness of the marks in the different areas).

It is not possible to determine with accuracy both the position and momentum of a particle. According to the uncertainty principle the producer of the uncertainty of a component of momentum as the Planck constant (h): ( $\Delta \mathrm{p} \mathrm{x} \Delta \mathrm{x} \sim \mathrm{h})$. Some say that during this time a lot can happen, the universe being one example.

Time estimation error: +1 '-39“

58 Nancy, 102. 
The score and the drawing show two different schemes: random motions and three white cubic frames. The white frames conceal the traces of the artist's fingers in a horizontally ordered sequence. The overlay of the geometric series upon the chaotic background corresponds to Morris's conception of time introduced in what seem to be two different chronological sequences for the piece; that is, his estimated set of minutes for drawing and its prolonged actuality, which does not accord with the apt rule of time, but lapses out of the ordained chronology. The white cubic forms are measured squares, articulating their geometrical overlay of finite perfection. They stand in contrast to the unexpected momentum of black traces. Morris explains their undefined composition rendering Heisenberg's uncertainty principle in quantum mechanics (1927), according to which any of a variety of mathematical inequalities asserts a fundamental limit to the precision with which certain pairs of physical properties of a particle, known as complementary variables, position and momentum -as noted in the score-can be known. Heisenberg's principle reveals a double division. First, the separation of knowledge from the physical world. If knowledge of every quantum theoretical quantity is maintained and derived from a coordinate system, the latter fixes a partial observation. Therefore, "a definite experiment can never give exact information on all quantum-theoretical quantities. Rather, it divides physical quantities into 'known' and ‘unknown' (or more or less accurately known quantities) in a way characteristic of the experiment in question." 59 The second division, which is derived from the first, is the division of position and momentum. In Nuclear Physics (1943), Heisenberg explains the problem of the principle of uncertainty "in its simplest form as follows: one can never know with perfect accuracy both of those two important factors which determine the movement of one of the smallest particles-its position and its velocity. It is impossible to determine accurately both the position and the direction and speed of a particle at the same instant." ${ }^{60}$ In fact, accurate evaluation of one is contingent upon uncertain knowledge of the other, since "if we determine experimentally its exact position at any given moment, its movement is disturbed to such a degree by that very experiment that we shall then be unable to find it at all. And conversely, if we are able to measure exactly the velocity of a particle, the picture of its position becomes totally blurred." ${ }^{61}$ In "The Physical Content of Quantum Kinematics and Mechanics," Heisenberg repeats this uncertainty as "the more precisely the position is determined, the less precisely the momentum is known, and conversely." 62 He maintains that the measurement of time does not only provide meaning to quantity, but also creates a particular value for this quan-

59 Werner Heisenberg, "The Physical Content of Quantum Kinematics and Mechanics," in Quantum Theory and Measurement, ed. John Archibald Wheeler and Wojciech Hubert Zurek (Princeton: Princeton University Press, 1983), 70.

60 Werner Heisenberg, Nuclear Physics, trans. Frank Gaynor and Amethe von Zeppelin (London: Methuen, 1953), 30.

61 Heisenberg, 30.

62 Heisenberg, "The Physical Content of Quantum Kinematics and Mechanics," 64. 
tity. In fact, "measurement" here means that a momentum is physically real via observation alone. Nevertheless, this palpable reality is always partial, since measuring momentum means that a position will be measured with some inaccuracy. ${ }^{63}$ Thus, we can only attribute discontinuous undecidability to the relations of position and momentum.

In Physics and Philosophy, Heisenberg claims there is no absolute universal time. In his thoughts about Kant, he refutes a priori forms of pure intuition and the law of causality. ${ }^{64}$ The uncertainty principle cast doubt on the reliability of any partial observation presented in a diagrammatic form which includes measurement, language, and knowledge. "What happens," Heisenberg wrote, "depends on our way of observing it or on the fact that we observe it." "M5 Morris's blind passage is a setting apart of both confident intervals and unmeasured intervals. They allude to several orders of time which are strictly concerned with the function of registering decisions. To return to Heisenberg, "the observer has only the function of registering decisions, i.e., processes in space and time, and it does not matter if the observer is an apparatus or a human being; but the registration, i.e., the transition from the 'possible' to the 'actual,' is absolutely necessary here."66 Time is bound to the register of the observer, who creates a reality via observation. Morris's blind-time actions determine the drawings' reality as uncertain relations which limit the possibility of simultaneously measuring time and position in accuracy. "Present time" marks an interval between the observer and the event at the moment of observation:

In the theory of relativity [...] future and past are separated by a finite time interval the length of which depends on the distance from the observer. [...] Therefore, an observer can at a given instant neither know of nor influence any event at a distant point which takes place between two characteristic times. The one time is the instant at which a light signal has to be given from the

63 Gilles Deleuze and Félix Guattari allude to Heisenberg's observer position and the possibility of the subjective interference of the measure with the measured. See Gilles Deleuze and Félix Guattari, What Is Philosophy?, trans. Hugh Tomlinson and Graham Burchell (New York: Columbia University Press, 1994), 129-30.

64 Werner Heisenberg, Physics and Philosophy: The Revolution in Modern Science, new ed. (New York: Harper, 1962), 49.

65 Heisenberg, 19. Heisenberg's use of the term anschaulichen is significant to understanding the role of perception in forming knowledge. Hilgevoord and Uffnik commentated anschaulichen as one of those German words that defy an unambiguous translation into other languages. In his biography of Heisenberg David C. Cassidy, refers to anschaulichen as "perceptual” (David C. Cassidy, Uncertainty: The Life and Science of Werner Heisenberg [New York: Freeman, 1992], 226). Literally, the closest translation of the term anschaulich is "visualisable." But, as in most languages, words that make reference to vision are not always intended literally. Seeing is widely used as a metaphor for understanding, especially for immediate understanding. Hence, anschaulich also means "intelligible" or "intuitive." See Jan Hilgevoord and Jos Uffink, "The Mathematical Expression of the Uncertainty Principle," in Microphysical Reality and Quantum Formalism: Proceedings of the Conference "Microphysical Reality and Quantum Formalism," Urbino, Italy, Sept. $25^{\text {th }}$-Oct. 3rd, 1985, ed. A. van der Merwe, F. Selleri, and G. Tarozzi (Dordrecht: Kluwer Academic Publishers, 1987): 911-14.

66 Heisenberg, Physics and Philosophy, 89. 
point of the event in order to reach the observer at the instant of observation. The other time is the instant at which a light signal, given by the observer at the instant of the observation, reaches the point of the event. The whole finite time interval between these two instants may be said to belong to the "present time" for the observer at the instant of observation. Any event taking place between the two characteristic times may be called "simultaneous" with the act of observation. ${ }^{67}$

\section{The Interval of Time Does Not See}

The intervals of time, senses, position and momentum, and text and action all allude to cutting out irrational and blind time or syncopated rhythm while keeping presupposed time a numerical measure at the opening of each score. In contrast to presupposed time, blind haptic time effects measure since the relations signified in Morris's "time errors" are unstable. These finite time intervals mark and frame the limit of the interval in relation to the first estimation and yet, initiating the haptic drawing time, they touch upon lapsed time, that cut-out irrational time. Morris's cut-out time and blind actions compose an empirical quasi-transcendental proposition. First, it is empirical insomuch as it is a mode of an auto-experience in time. Second, this auto-experience is the work of art in its technique. It shows its sense by touching itself touching its own sense. Time becomes the form of the action of differentiation, a temporal interval amid zones. Nancy's touch is also the place of non-seeing, lack, and deprived sense. It is posited as the spacing of the chiasmic intersection where all is withdrawn. In The Muses, Nancy returns to Heidegger's 1969 essay “Art and Space" to declare the origin and sense of spacing as an act of creation and the difference between zones. ${ }^{68}$ However, I will circumvent this move in order to concentrate on cut-out time. Morris's cut-out time is an instructive interval that as such touches upon itself, each time, again and again, in blind haptic spacing. It reverberates in Nancy's hyletic spiral as a temporal series indebted to the long tradition from Descartes to Freud via Lacan to Deleuze's split "I."

In order to understand Morris's interval of time, we must turn to Deleuze's critique of the temporal subject. Deleuze returns to Kant's critique of Descartes's think-

67 Heisenberg, 71.

68 The spatial nature of Nancy's heterogeneous haptic zones stems from his interpretation of Heidegger's construal of space as the absolute difference of appearance. In "Why Are There Several Arts?", Nancy cites Heidegger: "This is why Heidegger could write: 'We should learn to recognize that things themselves are places, and do not merely belong to place"'; see "Why Are There Several Arts?", 19. On the connection between place and space, Heidegger writes in "Art and Space" that a "clearing away (Räumen) is uttered therein. [...] Clearing away brings forth the free, the openness for man's settling and dwelling." See Martin Heidegger, "Art and Space," trans. Charles H. Seibert, Man and World 6 (1973): 5. See also Nancy's referral to Heidegger's On Time and Being, trans. Joan Stambaugh (New York: Harper \& Row, 1972), 23, and his "The Origin of the Work of Art," Poetry, Language, Thought, trans. Albert Hofstadter (New York: Harper \& Row, 1975), 75. 
ing subject, claiming that it rests on a succession of anterior time, the progression of the time of the Idea, Platonic, divine time. ${ }^{69}$ Plato and Aristotle thought of time as being cyclical and inseparable from the movement of physical bodies. Exposed to the externality of the outside, the cogito holds no innate ideas prior to the simultaneity of the soul. Kant critiques Descartes's move: if "I think" is a determination, then "I am/I exist" is an undeterminable determination; for we do not know how the indeterminate becomes determinate or the manner in which it will appear determinate. Hence, Kant rejects Descartes's claim that “I am a thinking substance.” Kant adds a component to Descartes's cogito: interior time. It is only through time that the indeterminable self becomes determinate. ${ }^{70}$ Pure and empty time cuts right through the consciousness of the subject. This fracture introduces a fundamental split in the subject: on one extreme, the active spontaneity of "I think" (towards unity/synthesis); on the other, the experiencing empirical self, effected by thought. The issue at hand is no longer succession, but a chiasm which is produced by a pure and empty form of time. I experience myself. The "I" effects itself in the form of time. This auto-affection is the interiorised difference between being and thought. It splits the subject into two: the empirico-transcendental doublet. The active synthesis of thought and the passive receptivity of effect; a touch, if you will, without synthesis.

Deleuze develops this cut, this interruption, in his third synthesis of time. No longer an a priori subjective "pure" form, time is rendered as a productive power constituted by a forceful, irrational cut. The cut draws together both before and after: thus, the totality of time. The cut thus determines the before and the after, which no longer rhyme:

We can then distinguish a more or less extensive past and a future in inverse proportion, but the future and the past here are not empirical and dynamic determinations of time: they are formal and fixed characteristics which follow a priori from the order of time, as though they comprised a static synthesis of time. The synthesis is necessarily static, since time is no longer subordinated to movement; time is the most radical form of change, but the form of change does not change. ${ }^{71}$

Exteriority is thus determined as the past before and the future after the cut. The pure present is the process of becoming equal to the event of experiencing internal difference. In the fourth section of Difference and Repetition, entitled "Asymmetrical Synthesis of the Sensible," Deleuze turns to Richard Dedekind's concept of the limit in the theory of real numbers:

69 Daniela Voss shows how for both Plato and Aristotle, time was defined as a "number of movement" counted by the celestial revolution of planets passing through certain "cardinal points." The uniform and circular motion of planets provided a means to mark off regular periods of time. Consequently, time was thought of as being cyclical and inseparable from the movement of physical bodies. See Daniela Voss, “Deleuze’s Third Synthesis of Time,” Deleuze Studies 7, no. 2 (2013):194-216. 70 Deleuze and Guattari, What Is Philosophy?, 31-32.

71 Gilles Deleuze, Difference and Repetition, trans. Paul Patton (New York: Columbia University Press, 1994), 89. 
In short, the limit must be conceived not as the limit of a function but as a genuine cut [coupure], a border between the changeable and the unchangeable within the function itself [...] close to the modern interpretation of calculus: the limit no longer presupposes the ideas of a continuous variable and infinite approximation. On the contrary, the notion of limit grounds a new, static and purely ideal [fictive, pure, passive] definition of continuity. ${ }^{72}$

Continuity, according to Dedekind, is composed of both rational and irrational numbers. The latter mark gaps that create discontinuity and incompleteness. He used a method of division, today known as the "Dedekind cuts," to divide a point in a line into two classes so that all the points in one class are always to the left of all the points in the other. Each cut determines one point, or alternatively, it can designate a gap between a rational number and an irrational quantity. Hence, cuts define irrational numbers. With these, he constructed an order of "real numbers" which included rational and irrational numbers. This order was devoid of the notions or intuitions of space and time and specifies an infinite and discrete multiplicity of elements.

In Dedekind's order, Deleuze saw a new, static, and purely ideal definition of continuity. He used this order to construct a time that is determined a priori and designates a static state of affairs. This is the Deleuzian a priori, a-subjective static synthesis of discrete elements (past and future moments) which are distributed by the cut. It may be characterised as a false infinity that includes an infinity of gaps, which are designated by the irrational cut; that is, the interstice between a series of rational numbers. They symbolise the irruption of the virtual event within the empirical continuum of space and the chronological succession of instants. These series of times bring together the past and future of becoming via contact with the outside.

A series of time is a cut; that is, difference-in-itself. In infinite repetition yet never the same, a series of time changes due to selections of desire or thought. Why desire? Morris's desire is dark, blind, and irrational. He returns to Lacan's drive as a force and a movement that strives towards completion and unity which, however, always remains incomplete. It moves and motivates the cyclic spiral. ${ }^{73}$ Stemming from Freud's Vorlust and the energetic cycle of the erotogenic zones, desire is at once an internal and an external force. Why thought? The temporal cut constituting thought demands a desire for self each time, eternally falling into the blind spot of incoherence and dissolution. Hence, Morris is performing a passage of the divided self, passing towards the unity of the "I," towards an image yet to come. Morris's proposition of the haptic cut, his passage of lapsed time, takes place in the blind haptic movement of pressured imprints. Again and again, there are hundreds of drawings, unspoken, inarticulate fingerprints. They pose the fractured self as a passive blind spot which generates the pictorial act. They reveal the sense of painting not as a universal concept, but as the singular self-portrait of Morris's plural touch-

72 Deleuze, 172.

73 Morris, "Writing with Davidson,” 622, 624. 
ings, plural cuts. Formally, the cut-out time(s) are intervals in an "impersonal and pre-individual" transcendental field, in which the vestige of the acting artist-marking his pressured weight towards an image-produces empirical formations by active synthesis. Each drawing, each set, each series is moved at the heart by syncopation, a dead heart that preforms and performs in passivity. This is the weak, passive form drifting amidst the effects of the touching senses of sense.

\section{Bibliography}

Anzieu, Didier. “Contre Lacan.” In Psychanalyser, edited by Didier Anzieu and René Kaës, 179-85.

Paris: Dunod, 2000.

Anzieu, Didier. The Skin-Ego. Translated by Naomi Segal. London: Karnac, 2016.

Anzieu, Didier. A Skin for Thought: Interviews with Gilbert Tarrab on Psychology and

Psychoanalysis. Translated by Daphne Nash Briggs. New York: Routledge, 2018.

Aristotle. The Complete Works of Aristotle. Edited by Jonathan Barnes. 2 vols. Princeton: Princeton University Press, 1984.

Aristotle. De anima. Translated by Mark Shiffman. Newburyport, MA: Focus Publishing, 2011.

Beckett, Samuel. Murphy. Edited by J.C.C. Mays. New ed. London: Faber and Faber, 2009.

Beckett, Samuel. The Unnamable. New York: Grove Press, 1958.

Bochner, Mel. Solar Systems \& Rest Rooms: Writings and Interviews, 1965-2007. Cambridge, MA: MIT Press, 2008.

Boulter, Jonathan. “Does Mourning Require a Subject?" Modern Fiction Studies 50, no. 2 (Summer 2004), 332-50.

Cassidy, David C. Uncertainty: The Life and Science of Werner Heisenberg. New York: Freeman, 1992.

Cohn, Ruby. A Beckett Canon. Ann Arbor: University of Michigan Press, 2001.

Criqui, Jean-Pierre. "Drawing from the Heart of Darkness: Robert Morris' Blind Time." In Blind Time Drawings, 1973-2000. Edited by Jean-Pierre Criqui, 11-26. Prato: Centro per l'Artr Contemporanea Luigi Pecci, 2005.

Davidson, Donald. "Agency." In Donald Davidson, Essays on Actions and Events, 43-62. 2nd ed. Oxford: Clarendon Press, 2001.

Davidson, Donald. “The Third Man." Critical Inquiry 19, no. 4 (1993): 607-16.

Davies, Paul. Beckett and Eros: Death and Humanism. Basingstoke: Macmillan Press; New York: St. Martin's Press, 2000.

Deleuze, Gilles, Difference and Repetition. Translated by Paul Patton. New York: Columbia University Press, 1994.

Deleuze, Gilles, and Félix Guattari. What Is Philosophy? Translated by Hugh Tomlinson and Graham Burchell. New York: Columbia University Press, 1994.

Dolar, Mladen. “Kafka's Voices.” In Lacan: The Silent Partners, edited by Slavoj Žižek, 312-35. London: Verso, 2003.

Duve, Thierry de. "Michael Snow: The Deictics of Experience and Beyond." Parachute 78 (AprilJune, 1995): 28-41.

Freud, Sigmund. "Formulations on the Two Principles of Mental Functioning." In The Standard Edition of the Complete Psychological Works of Sigmund Freud, Volume 12 (1911-1913): The Case of Schreber, Papers on Technique and Other Works, edited by James Strachey et al., 218-26. London: The Hogarth Press, 1958. 
Freud, Sigmund. "Three Essays on the Theory of Sexuality." In The Standard Edition of the Complete Psychological Works of Sigmund Freud, Volume 7 (1901-1905): A Case of Hysteria, Three Essays on Sexuality and Other Works, edited by James Strachey et al., 125-245. London: The Hogarth Press, 1953.

Gregoric, Pavel. Aristotle on the Common Sense. Oxford: Oxford University Press, 2007.

Heidegger, Martin. "Art and Space." Translated by Charles H. Seibert. Man and World 6 (1973): 38.

Heidegger, Martin. On Time and Being. Translated by Joan Stambaugh. New York: Harper \& Row, 1972.

Heidegger, Martin. "The Origin of the Work of Art." In Poetry, Language, Thought, translated by Albert Hofstadter, 15-86. New York: Harper \& Row, 1975.

Heisenberg, Werner. Nuclear Physics. Translated by Frank Gaynor and Amethe von Zeppelin. London: Methuen, 1953.

Heisenberg, Werner. "The Physical Content of Quantum Kinematics and Mechanics." In Quantum Theory and Measurement, edited by John Archibald Wheeler and Wojciech Hubert Zurek, 6286. Princeton: Princeton University Press, 1983.

Heisenberg, Werner. Physics and Philosophy: The Revolution in Modern Science. New ed. New York: Harper, 1962.

Heller-Roazen, Daniel. The Inner Touch: Archaeology of a Sensation. Paperback ed. New York: Zone Books, 2009.

Hilgevoord, Jan, and Uffink Jos. "The Mathematical Expression of the Uncertainty Principle." In Microphysical Reality and Quantum Formalism, Volume 1: Proceedings of the Conference “Microphysical Reality and Quantum Formalism," Urbino, Italy, Sept. $25^{\text {th }}$-Oct. 3rd, 1985, edited by A. van der Merwe, F. Selleri, and G. Tarozzi, 911-14. Dordrecht: Kluwer Academic Publishers, 1987.

Johansen, T.K. Aristotle on the Sense-Organs. Cambridge: Cambridge University Press, 1997.

Krens, Thomas. "The Triumph of Entropy." In Robert Morris: The Mind/Body Problem, edited by Thomas Krens and Rosalind Krauss, xvii-xxxi. New York: Solomon R. Guggenheim Foundation, 1994.

Kristeva, Julia. "Le théâtre modern n'a pas lieu." 34/44: Cahiers de recherche des sciences des textes et documents 3 (1977): 13-16.

Lacan, Jacques. The Four Fundamental Concepts of Psychoanalysis. Translated by Alan Sheridan. New York: W.W. Norton \& Company, 1978.

Lafrance, Marc. "From the Skin Ego to the Psychic Envelope: An Introduction to the Work of Didier Anzieu." In Skin, Culture and Psychoanalysis, edited by Sheila L. Cavanagh, Angela Failler, and Rachel Alpha Johnston Hurst, 16-44. New York: Palgrave Macmillan, 2013.

Lafrance, Marc. "Skin and the Self: Cultural Theory and Anglo-American Psychoanalysis." Body and Society 15, no. 3 (2009): 3-24.

Leary, Timothy. "She Comes in Colors." Playboy 153 (September 1966). Reprinted in The Politics of Ecstasy, 99-132. Reprint ed. London: Paladin, 1972.

Legge, Elizabeth M. Michael Snow: Wavelength. London: Afterall Books, 2009.

Lippard, Lucy. R. “Perverse Perspectives.” Art International 11, no. 3 (1967): 28-33.

Massie, Pascal. "Touching, Thinking, Being: The Sense of Touch in Aristotle's De anima and Its Implications." Minerva: An Internet Journal of Philosophy 17 (2013): 74-101.

Morris, Robert. Continuous Project Altered Daily: The Writings of Robert Morris. Cambridge, MA: MIT Press, 1993.

Morris, Robert. "Writing with Davidson: Some Afterthoughts after Doing Blind Time IV: Drawing with Davidson." Critical Inquiry 19, no. 4 (1993): 617-27.

Nancy, Jean-Luc. The Discourse of the Syncope: Logodaedalus. Translated by Saul Anton. Stanford: Stanford University Press, 2008. 
Nancy, Jean Luc. "Why Are There Several Arts, Not Just One?" In The Muses, translated by Peggy Kamuf, 1-40. Stanford: Stanford University Press, 1996.

Panofsky, Erwin. Perspective as Symbolic Form. Translated by Christopher S. Wood. New York: Zone Books, 1991.

Reynolds, Ann. "Enantiomorphic Models." In Robert Smithson. Edited by Eugenie Tsai and Cornelia Butler, 137-41. Berkeley: University of California Press, 2004.

Segal, Naomi. Consensuality: Didier Anzieu, Gender and the Sense of Touch. Amsterdam and New York: Rodopi, 2009.

Shepherdson, Charles. “Aesthetic 'Sense' in Kant and Nancy." New Literary History 48, no. 2 (2017): 197-221.

Smithson, Robert. Robert Smithson: The Collected Writings. Edited by Jack Flam. Berkeley: University of California Press, 1996.

Surin, Kenneth. "Getting the Picture: Donald Davidson on Robert Morris's Blind Time Drawings IV (Drawing with Davidson)." The South Atlantic Quarterly 101, no. 1 (2002): 132-69.

Voss, Daniela. "Deleuze's Third Synthesis of Time." Deleuze Studies 7, no. 2 (2013): 194-216.

Žižek, Slavoj. Disparities. London: Bloomsbury Academic, 2016. 